\title{
Competência em informação para comunidades: empoderamento e protagonismo social
}

\begin{abstract}
Maria Giovanna Guedes Faria ${ }^{I}$
\end{abstract}
Aida Varela Varela ${ }^{I I}$

Isa Maria Freire ${ }^{I I I}$

${ }^{I}$ Universidade Federal do Ceará, Fortaleza, CE, Brasil.

Professora do Departamento de Ciências da Informação

da Universidade Federal do Ceará. Doutora em Ciência da Informação

pela Universidade Federal da Bahia.

II Universidade Federal da Bahia, Salvador, BA, Brasil.

Professora do Programa de Pós-Graduação em Ciência

da Informação da Universidade Federal da Bahia.

Doutora em Ciência da Informação pela Universidade de Brasília

${ }^{I I I}$ Universidade Federal da Paraíba, João Pessoa, PB, Brasil.

Professora do Departamento de Ciências da Informação

da Universidade Federal do Ceará. Doutora em Ciência da Informação

pela Universidade Federal da Bahia.

http://dx.doi.org/10.1590/1981-5344/2614

Apresenta resultado de pesquisa, que objetivou desenvolver competências em informação em moradores da Comunidade Santa Clara, em João Pessoa, por meio de estratégias de mediação, agindo com base no diálogo e na alteridade. Para tal, implementou-se uma ação de informação concretizada através de um projeto de capacitação denominado preparatório para entrevista de trabalho, produzido a partir de experiência vivenciada durante doutorado-sanduíche na Itália. $O$ percurso metodológico foi pautado na aplicação da abordagem qualitativa, pesquisa participante, observação participante, além do uso de entrevistas. Para tratar os dados coletados, utilizou-se a análise de conteúdo e recursos de codificação de dados em três níveis: antes, durante e após a capacitação. Os resultados demonstram que as estratégias de mediação da informação forneceram subsídios teóricos para transitar na Ciência da Informação, possibilitando o exercício da reflexão e a 
potencialização do protagonismo social nos moradores, ao passarem por alguns estágios de empoderamento da informação, ao se apropriarem dela e a utilizarem para desenvolver competências em informação. Conclui-se que a ação de informação realizada para e com os moradores produzem conhecimentos, principalmente, a interação dos sujeitos com o meio onde vivem, a partir da carga cultural e histórica que eles trazem, o que está intrinsicamente ligado à prática social.

Palavras-chave: Competência em informação. Mediação da informação. Comunidade. Protagonismo social. Empoderamento.

\section{Information literacy for communities: empowerment and social protagonism}

It presents research results, which aimed to develop information skills in residents of the Santa Clara Community, in João Pessoa, through mediation strategies, acting based on dialogue and otherness. For this, an information action was implemented through a training project called preparatory for job interview, produced from experience during doctorate-sandwich in Italy. The methodological approach was guided by the application of qualitative approach, participatory research, participant observation, and the use of interviews. To process the data collected, we used the analysis of content and data encryption capabilities at three levels: before, during and after training. The results show that information mediation strategies provided theoretical support for transit in Information Science, enabling the exercise of reflection and the enhancement of social involvement on residents to go through some empowerment stages of information, to take ownership of it and use to develop skills in information. It is concluded that the information of action taken and to produce knowledge with the locals, especially the interaction of individuals with the environment where they live, from the cultural and historical burden they bring, which is intrinsically linked to social practice.

Keywords: Information literacy. Mediation of information. Community. Social leadership. Empowerment. 
Recebido em 09.11.2015 Aceito em 22.03.2019

\section{Introdução}

Este artigo apresenta os resultados de pesquisa de doutorado em Ciência de Informação (CI), a qual objetivou desenvolver competências em informação nos moradores da Comunidade Santa Clara, localizada em João Pessoa, de modo que os mesmos pudessem se empoderar da informação de que necessitavam e se tornassem, progressivamente, protagonistas da realidade que vivenciam. Para isso, empregou-se a mediação da informação durante a atuação dentro do campo de pesquisa, agindo com base na alteridade, ou seja, no cuidado com o outro.

A experiência adquirida durante um doutorado-sanduíche realizado na comunidade italiana Rione Sanità, na cidade de Nápoles, portou a esta pesquisa elementos para a atuação na Santa Clara, pois observou-se que na Itália a mobilização de indivíduos e de grupos é constituída para aqueles que anseiam por retecer suas vidas e a realidade que os rodeia, colocando em prática ações concretas refletidas de forma cooperada e com metas consolidadas, promovendo uma leitura permanente das condições do contexto, um acompanhamento constante de processos, uma presença assídua nos pontos de fragilidade, empreendendo ações voltadas para a escolarização e para a formação. (FARIAS; FREIRE, 2014).

Dessa forma, compreendeu-se que a ação a ser promovida na Santa Clara precisaria ser pautada na formação, provocando nos moradores o interesse em se empoderar efetivamente da informação, propiciando o surgimento da consciência do valor que a informação pode ter na vida deles, ao suprir suas necessidades. Em razão disso, entende-se que a mediação serve como estímulo e exerce uma função primordial de promover um diálogo com os moradores, de indicar possíveis caminhos para o protagonismo social ${ }^{1}$. Entretanto, não se pode pensar na perspectiva de que os sujeitos são seus próprios mediadores, mas pensou-se em um trabalho em conjunto no campo de pesquisa, uma construção coletiva inspirada na teoria da ação libertadora freireana, de procurar ouvir/sentir o que os moradores anseiam, visualizando a comunidade como um lugar repleto de pessoas que exprimem de diversas formas os seus desejos.

Quando os moradores se apropriam da informação inicia-se outra etapa, a discussão do valor da informação, da autorreflexão do que significa ter acesso e usar a informação para benefício próprio, isso pode ser caracterizado como sendo o empoderamento. A próxima etapa seria alcançar o protagonismo social, ao deslocar seus atores para o papel

O conceito de protagonismo tem um significado relacional, na medida em que só pode ser compreendido em relação aos diferentes sujeitos, envolvidos num acontecimento, como explica Klein (2009). O que significa dizer que, este conceito visa deslocar seus atores para o papel principal, por revelar uma dimensão pessoal e ao mesmo tempo plural de convivência com o outro, com a comunidade a qual pertence, promovendo ações de diversos níveis, inclusive informacionais, e potencializado uma dinâmica social e cultural no seu contexto, e na sociedade. (FARIAS, 2015). 
principal, por revelar uma dimensão pessoal e ao mesmo tempo plural de convivência com o outro. Os protagonistas são, segundo Perrotti e Pieruccini (2007), simultaneamente sujeitos e objetos dos processos em que estão inseridos, produtores e criadores de significados, sentidos e práticas sociais.

Destarte, expõe-se aqui um recorte dos resultados, com intuito de apresentar as competências em informação adquiridas pelos sujeitos da pesquisa, durante uma capacitação escolhida pelos mesmos durante reuniões na própria comunidade, caracterizada nesta pesquisa como uma ação de informação, a qual objetivou prepará-los para uma entrevista de trabalho, tendo em vista o alto índice de desemprego na localidade. A montagem e a aplicação da capacitação tiveram como aporte teórico da mediação da informação, com aplicação metodológica da abordagem qualitativa, pesquisa participante, observação participante com uso de entrevistas para coleta de dados. Para tratar os dados coletados, utilizouse a análise de conteúdo de Bardin (2009) e os recursos da codificação de dados em três níveis conforme Tavares (2011). Selecionou-se o terceiro nível de codificação para figurar nesta comunicação, o qual trata da avaliação da aprendizagem; conscientização da possibilidade de automodificabilidade; e empoderamento das informações.

\section{Mediação e competência em informação}

O aporte teórico-conceitual da mediação da informação ao ser aplicado para o desenvolvimento de competências em informação traz em si, conforme Gomes (2014, p. 52), o "[...] sentido de compartilhamento, de cooperação, de abertura ao diálogo e ao movimento que desestabiliza e estabiliza conhecimentos, de abertura à crítica e à criatividade". Segundo Almeida (2009, p. 16) a mediação está ligada às conexões estabelecidas entre as ações sociais e as motivações (individuais/coletivas), podendo ser vista "[...] como sinônimo de processos de interlocução e/ou interação entre os membros de uma comunidade, por meio dos quais os laços de sociabilidade são estabelecidos e alimentados."

Na visão de Varela (2008, p. 36), os elementos que compõem a mediação e que vão permitir a consonância de objetivos entre o que busca o usuário e o que lhe oferta o profissional acontecem bem antes da busca, "[...] mediante um processo dialógico em que o profissional se antecipa ao desejo do usuário e organiza o estoque de informação, dialogando com este usuário potencial".

O objetivo implícito da mediação da informação se concentra, de acordo com Gomes (2014, p. 55), no desenvolvimento do protagonismo social e esta é dependente do processo dialógico, pois a mediação "[...] representa uma ação que depende do nível de conscientização do agente que a realiza em relação a esse objetivo, como também quanto ao seu papel protagonista, que nessa condição interfere no meio e se constitui em sujeito da estética, da ética e da humanização do mundo". Já Almeida Júnior (2015) ressalta que a mediação da informação é toda ação de 
interferência, que objetiva a apropriação de informação. Para que essa apropriação pudesse existir no campo de pesquisa, implantou-se uma ação de informação (a capacitação) com objetivo de promover o desenvolvimento competências em informação, necessárias para que estes moradores passem a pensar e atuar como cidadãos, como protagonistas. Isso pode ocorrer, pois conforme Perrenoud (1999) a noção de competência está direcionada para a capacidade de agir eficazmente em um determinado tipo de situação, colocando em ação e em sinergia vários recursos cognitivos complementares, entre os quais estão os conhecimentos, representações da realidade, que construímos e armazenamos a partir de nossa experiência e de nossa formação.

Para alcançar uma construção compartilhada de conhecimentos criada a partir de competências, promoveu-se para os moradores uma capacitação denominada "preparatório para entrevista de trabalho", que teve como objetivo principal: estimular, por meio de conteúdos e metodologias específicas, o desenvolvimento da consciência nos participantes da importância de se empoderar das informações necessitadas e transformá-las em ação, um processo que teve a mediação como base em todas as fases.

Ao estudar Le Boterf (2003), entendeu-se que a temática da capacitação escolhida está em consonância com as reflexões deste autor, já que as competências, segundo ele, nascem no âmbito trabalhista, e por isso mesmo, a empregabilidade relaciona-se à capacidade que o sujeito tem de construir competências, as quais podem aumentar as chances do sujeito em obter novas oportunidades de trabalho, e de se preparar para situações de avaliação, que ocorrem constantemente nas empresas.

Ao compreender a necessidade de integrar múltiplos saberes, desenvolvendo um conjunto de conhecimentos e habilidades (competências), o indivíduo pode se sentir cada vez mais preparado para o mercado de trabalho, e consequentemente, para exercer sua cidadania e estimular os componentes do seu grupo a também exercê-la, ao acessar e usar informações que necessitam, promovendo ações em benefício próprio e da comunidade. Neste contexto, ratifica-se a relevância da aplicação da mediação da informação, "[...] pois os sujeitos envolvidos no processo de mediação efetiva da informação sentem-se acolhidos e reconhecidos como participantes ativos, como protagonistas da informação." (GOMES, 2014, p. 52).

O mediador que atua em uma comunidade pode ajudar os moradores, levando ao conhecimento dos interessados os aspectos que envolvem o empoderamento e a necessidade de discussão de todas as informações necessárias para se pleitear políticas, projetos e ações. Para corroborar com essa questão, Gohn (2004) assevera que o empoderamento envolve procedimentos, que tenham a capacidade de gerar processos de desenvolvimento autosustentável, com a mediação de agentes externos, a exemplo de profissionais da informação e de educadores sociais, atores fundamentais na organização e o desenvolvimento dos projetos. Dessa forma, a ação de informação empreendida no campo de pesquisa prima pelo diálogo e compreensão, 
visando identificar as brechas onde o mediador/pesquisador pode atuar junto ao coletivo, tentando não deixar que pela ausência de informação haja a decadência social.

\section{Delineamento metodológico}

Nesta investigação, todo o caminhar dentro do campo de pesquisa foi conduzido pelos pressupostos metodológicos da abordagem qualitativa. A razão para essa escolha se deu, porque a pesquisa qualitativa não tenta aplicar conceitos pré-existentes, e os instrumentos e técnicas de pesquisa são elaborados a partir do que o pesquisador sente ao conhecer os sujeitos e a realidade que os cerca no campo de pesquisa.

Entende-se que isso faz parte de uma postura socialmente responsável, a qual a Ciência da Informação está cada vez mais em sintonia, uma área que procura entender as necessidades dos usuários/sujeitos e qual a relevância da informação em seu cotidiano, em sua vida. O método utilizado envolveu a participação, esse elemento determina, de acordo com Brandão (1983, p. 12), "[...] um compromisso que subordina o próprio projeto científico de pesquisa ao projeto político dos grupos populares, cuja situação de classe, cultura ou história se quer conhecer porque se quer agir."

Para coletar os dados fez-se uso da observação participante, diário de campo, formulário de prospecção e roteiro de entrevista. Esses instrumentos de pesquisa foram utilizados antes, durante e após a capacitação, objetivando analisar quais competências foram desenvolvidas nos moradores da comunidade e como se encontrava o estado cognitivo desses sujeitos, suas expectativas em relação ao aprendizado antes de participarem da capacitação. É preciso ressaltar, que o objetivo era de que esses moradores se tornem disseminadores das competências em informação adquiridas, as quais foram direcionadas para o desenvolvimento de habilidades sociais, cognitivas e tecnológicas. Por esta razão, a capacitação foi aplicada, sobretudo, para as pessoas consideradas as mais ativas da comunidade. O grupo é constituído por mulheres com idade entre 14 e 61 anos, o que demonstra mais uma vez a liderança feminina no contexto das comunidades. Algumas delas criam os filhos sozinhas e trabalham como diaristas para manter a casa, mas estão à procura de oportunidades melhores. Outras participantes da capacitação são estudantes, nunca trabalharam e procuram o primeiro emprego, por isso buscam se preparar para o momento da primeira entrevista. No decorrer do texto, as entrevistadas são denominadas de E1 a E10.

Ainda foi utilizado o grupo focal após a capacitação, uma técnica de pesquisa qualitativa, que se caracteriza como uma prática social, e pode estimular voz da Comunidade. De acordo com Veiga e Gondim (2001, p. 8), essa técnica possibilita "[...] compreender a construção das percepções, atitudes e representações sociais de grupos humanos acerca de um tema específico $[\ldots]^{\prime \prime}$, tendo como principais características proporcionar condições aos participantes da pesquisa em "[...] exercer um papel mais ativo nos processos de produção do conhecimento e, ao 
mesmo tempo, oferecer-Ihes oportunidade de conscientização de sua situação atual, dando-lhes maior poder de transformação."

O grupo focal nesta pesquisa foi constituído pelos moradores que participaram da capacitação, e foi mediado pela instrutora da capacitação e pela pesquisadora, ambas se prepararam para este momento, planejando as questões de organização, a produção de anotações das expressões e gestos diante de cada questionamento dos participantes. A transcrição do material coletado também foi realizada pela pesquisadora.

Durante a preparação do conteúdo e dos recursos didáticos, considerou-se as características da localidade, da cultura e da lógica do pensamento dos moradores para que o aprendizado ocorresse de forma intensa e valorizada por parte do grupo. Para isso, os métodos, técnicas e instrumentos utilizados durante a capacitação objetivavam ser atrativos e motivadores evitando assim, a falta de interesse dos participantes.

O plano de curso e a ementa da capacitação foram delineados diante dessa perspectiva de atrair e motivar os participantes, de estimular o aprendizado e o desenvolvimento de competências em informação. Vale ressaltar que a ministrante da capacitação foi devidamente treinada e todo material utilizado foi produzido pela pesquisadora, que acompanhou cada etapa da realização da capacitação.

O roteiro de entrevista foi aplicado a cada participante, sendo estruturado de acordo com o plano de aula. Decidiu-se por produzir um roteiro que proporcionou maior flexibilidade durante as entrevistas. Nessa perspectiva, é preciso entender e considerar a cultura e a dinâmica de cada comunidade. Por meio da capacitação foi possível identificar, a partir dos instrumentos de pesquisa e do roteiro de entrevista, as habilidades e conhecimentos prévios de cada morador participante. Esse roteiro objetivou avaliar, quais as competências que os participantes detinham antes da capacitação.

Para analisar os dados coletados durante todas as ações dentro do campo de pesquisa, empregou-se a análise de conteúdo (AC) de Bardin (2009), cujo objetivo se concentra em um aprofundamento, uma "[...] descoberta do que está por trás dos conteúdos manifestos, indo além das aparências do que está sendo comunicado [...]", como afirma Gomes (1994, p. 74). Ao analisar o material coletado, descobriu-se novas interpretações, que não estavam aparentes no momento da coleta, uma ocasião para fazer com que as falas dialogassem entre si e com os personagens envolvidos neste processo de desnudamento dos conhecimentos por eles disseminados.

\subsection{Processo de montagem da capacitação}

A trajetória adotada durante a montagem da capacitação "Preparatório para entrevista de trabalho" foi conduzida por meio do diálogo, da mediação e das construções socialmente elaboradas que o conhecimento pode ser socialmente construído e o real sentido da alteridade pode ser colocado em prática na relação de interação social com o outro, no contato, no processo de comunicação, e nessa mediação 
existente entre o "eu" e o "outro", o que levaria a um autoconhecimento, fundamental para o desenvolvimento de competências em diversos âmbitos, inclusive e principalmente, informacionais.

Enfatiza-se ainda que, antes da capacitação ser aplicada, analisouse o perfil dos interessados, por meio de entrevistas, com o objetivo de direcionar o conteúdo e a metodologia, tomando como base o conhecimento prévio dos participantes, se preocupando com os aspectos cognitivos e sociais dos sujeitos, no intuito de possibilitar para eles o desenvolvimento de competências para acessar e usar criticamente a informação.

Ressalta-se que essa capacitação objetivou: apresentar ao participante a forma adequada do vestuário e da higiene pessoal; orientar como se comunicar adequadamente (linguagem verbal e corporal); como desenvolver a capacidade de antever possíveis questionamentos do entrevistador; mostrar a relevância da habilidade de ser proativo quanto às informações a serem respondidas; conscientizar sobre a importância de ter um bom currículo; mostrar qual o perfil de profissional que as empresas buscam; e ao final foram indicadas fontes de informação para futuras pesquisas sobre a temática.

Atenção desta pesquisa se voltou para a organização do conhecimento que foi disseminado, e na preparação do instrutor da capacitação, que teve o entendimento de que toda essa trajetória poderia ser desfeita e refeita, e ele deveria estar preparado para isso. Era preciso que esse mediador transcendesse, fosse além para localizar as "brechas", pois conforme Vygotsky (1991) para se construir conhecimento é preciso uma ação partilhada significando um processo de mediação entre sujeitos, através da interação, das relações com os outros e seu meio social, por isso, que qualquer função psicológica superior, se foi externa significa que ela foi social, antes de se tornar função, ela foi uma relação social entre duas pessoas.

Para definir o que significa o termo capacitação e quais as atitudes, habilidades e competências necessárias para aplicá-la, seguiu-se as conceituações ressaltadas por Flem (2004), segundo as quais a capacitação é uma ferramenta que, por meio de planejamento apropriado, torna-se indutora de mudanças, pois encoraja a reflexão crítica com aplicação de instrumentos didáticos direcionados a construção de valores compartilhados, de saberes, conhecimentos, competências e habilidades, possibilitando mudanças de atitudes nos participantes, envolvendo ainda um processo pedagógico, que visa estimular a percepção crítica do mundo, preparando os indivíduos para agir, transformar e responder às mudanças e desafios do contexto.

Durante a trajetória de montagem da capacitação, refletiu-se qual seria a melhor forma de avaliar as possíveis competências adquiridas pelos moradores. A partir dos dados coletados durante a pesquisa de campo, procedeu-se com a análise destes dados ponderando sobre os objetivos específicos/temas que compõem a capacitação e suas respectivas competências (as competências desejadas pela pesquisa), tendo como parâmetro as definições de Le Boterf. 
Ainda em relação ao tratamento dos dados, fez-se uso de um esquema (Quadro 1) desenvolvido por Tavares (2011), para analisar os níveis de codificação de dados coletados durante a pesquisa de campo, com foco no terceiro nível, que inclui a aprendizagem, 0 comprometimento, o engajamento e a cidadania, o que propiciou a compreensão in loco do conceito de Pinto Molina (2005, p. 8) sobre aprendizagem, a qual se baseia em competências que refletem a capacidade do 'aprendente' colocar "[...] em prática de maneira integrada, habilidades, conhecimentos e atitudes de enfrentar-se e poder resolver problemas e situações, indicando o grau de preparação, suficiência e responsabilidade."

Quadro 1 - Níveis de codificação de dados

\begin{tabular}{|c|c|c|}
\hline $1^{\circ}$ nível de codificação & $\begin{array}{l}2^{\circ} \text { nível de } \\
\text { codificação }\end{array}$ & $3^{\circ}$ nível de codificação \\
\hline Como usar & \multirow{4}{*}{ Instrução } & \multirow{4}{*}{ Aprendizagem } \\
\hline Como fazer & & \\
\hline Como definir & & \\
\hline \multirow{2}{*}{\multicolumn{3}{|c|}{$\begin{array}{l}\text { Como agir } \\
\text { Trocar conhecimentos e experiências }\end{array}$}} \\
\hline & & \\
\hline Fazer tarefa de forma diferente & $\begin{array}{l}\text { Mudança de } \\
\text { comportamento }\end{array}$ & Aprendizagem \\
\hline Realizar tarefas & Participação & \multirow[b]{2}{*}{ Comprometimento } \\
\hline Estar presente/permanecer & Comparecimento & \\
\hline Definir papéis & \multirow{3}{*}{ Organização } & \multirow{3}{*}{ Engajamento } \\
\hline Definir cronograma & & \\
\hline Introduzir novas atividades & & \\
\hline Fazer apresentação pessoal & \multirow[b]{2}{*}{ Organização } & \multirow[b]{2}{*}{ Engajamento } \\
\hline Fazer apresentação do trabalho & & \\
\hline Sugerir alteração & \multirow{6}{*}{ Trabalho em equipe } & \multirow{6}{*}{ Engajamento } \\
\hline Discutir no contexto da atividade & & \\
\hline Negociar e buscar consenso & & \\
\hline Saber ouvir, falar e aceitar diferenças & & \\
\hline Incluir pessoas na discussão & & \\
\hline Dar/considerar opiniões e pontos de vista & & \\
\hline Apresentar/sintetizar os trabalhos & \multirow{4}{*}{$\begin{array}{l}\text { Autonomia, } \\
\text { emancipação e } \\
\text { dignidade }\end{array}$} & \multirow{8}{*}{ Cidadania } \\
\hline Apresentar críticas construtivas & & \\
\hline $\begin{array}{l}\text { Usar criticamente informação para tomar } \\
\text { decisão e solucionar problemas }\end{array}$ & & \\
\hline Exigir direitos sociais & & \\
\hline $\begin{array}{l}\text { Discutir sobre eficiência de } \\
\text { processos/atividades }\end{array}$ & \multirow[t]{4}{*}{ Conscientização } & \\
\hline Perceber/discutir resultados & & \\
\hline Avaliar a aprendizagem & & \\
\hline Avaliar, refletir e dar feedback & & \\
\hline
\end{tabular}

Fonte: TAVARES, 2011.

A partir das categorias estabelecidas, verificou-se se e como os moradores atingiram os três níveis de codificação, com especial atenção para o último, o que para esta investigação significa se apropriar da informação e implica, conforme Perrotti e Pieruccini (2007), em atuação e afirmação dos sujeitos nas dinâmicas de negociação de significados e na transação de significados que diferencia e constitui os negociadores como sujeitos da cultura, protagonistas, cidadãos. Essa apropriação só pode 
ocorrer por meio da aprendizagem de novos saberes informacionais, o que deve incluir, segundo Santos e Pieruccini (2012, p. 107), um programa de "[...] ações pedagógicas que valorizem a autonomia e o protagonismo dos sujeitos no processo social de produção de saber, de modo que sejam capazes de transformar, autonomamente, os produtos de sua criação em bens simbólicos."

Para se chegar a tal inferência, adotou-se o seguinte percurso para a coleta de dados: inicialmente realizou-se uma entrevista précapacitação, com objetivo de compreender qual o nível de conhecimento dos participantes em relação à temática. O segundo momento de coleta de dados ocorreu durante a capacitação com a observação participante, momento em que foram registradas as informações no diário de campo. A última etapa também contou com o diário de campo, e aconteceu durante a dinâmica de grupo, que foi seguida pelo grupo focal. Essa dinâmica simulou uma entrevista de trabalho, e a partir da atuação de cada morador como candidato a uma vaga, foi sendo enfatizado o que havia sido apreendido durante a capacitação, o que permitiu compreender o quanto os participantes haviam absorvido do que fora disseminado. Durante o grupo focal, utilizou-se um roteiro de entrevista direcionado a compreender a opinião dos participantes quanto ao conteúdo, metodologia e formato da capacitação.

\section{Resultados e discussão}

Os dados coletados oralmente foram transcritos, respeitando-se os momentos de silêncio dos participantes e o modo de se expressarem. Em seguida, passaram por uma leitura atenta da pesquisadora, visando observar as informações mais relevantes, o que os participantes sempre repetiam, ou seja, as informações recorrentes. Além dessas informações orais, as observações descritas no diário de campo auxiliaram durante a interpretação dos dados. Algumas informações coletadas já foram descritas e interpretadas nas subseções precedentes.

Empregou-se quadros para apresentar e interpretar os dados coletados. Cada um deles equivale a uma etapa de estágio cognitivo, ou seja, a estágios de compreensão dos participantes da capacitação. Eles foram inspirados nos níveis de codificação de Tavares (2011). O primeiro nível de codificação traz dados coletados na entrevista pré-capacitação, com objetivo de compreender qual o estágio de conhecimento dos participantes em relação à temática. O segundo quadro apresenta dados obtidos durante a capacitação com a observação participante, momento em que foram registradas as informações no diário de campo. A última etapa aconteceu ao longo da dinâmica de grupo, a qual foi seguida pelo grupo focal.

A partir das categorias estabelecidas, verificou-se os indícios de como os moradores atingiram os três níveis de codificação. O primeiro nível de codificação tem como objetivo mostrar qual o conhecimento que os participantes detinham antes da capacitação, o que desejavam aprender, qual a ideia que faziam antes de adquirirem esse conhecimento, 
foi estruturado em cinco categorias, acompanhadas das falas dos participantes, quais sejam: reconhecimento da necessidade de aprender; conhecimentos prévios; compartilhar/trocar conhecimentos e experiências; comportamento/busca informacional; e desejo de aprender. O segundo nível de codificação trata dos dados coletados e anotados no diário de campo durante a exposição oral e a dinâmica de grupo. As categorias deste nível são: engajamento; participar, ouvir e aceitar opiniões; e aprendizagem.

O terceiro nível de codificação - o qual foi escolhido para figurar nesta comunicação - trata das informações coletadas no grupo focal. 0 roteiro foi direcionado para as seguintes categorias apresentadas no Quadro 2: avaliação da aprendizagem; conscientização da possibilidade de automodificabilidade; e empoderamento das informações.

Ao avaliar o formato da capacitação e o conteúdo disseminado, os participantes falaram o quão válida foram as informações propagadas, a exemplo de E5, que disse estar saindo da capacitação com outro pensamento. Já E8 ressaltou que, a instrutora explicou bem o conteúdo. As participantes tiveram essa experiência e essa impressão, porque se tratou de uma aprendizagem mediada, que conforme Feuerstein (1980) tem como estratégia metodológica o diálogo e a interação constante entre o mediador e o 'aprendente', onde existe a intencionalidade de possibilitar ao indivíduo transcender os estímulos e as experiências de vida, respeitando as manifestações culturais de cada realidade, procurando potencializar a aprendizagem com base nas questões/problemas diários dos indivíduos.

Alguns dos problemas diários enfrentados pelos moradores estão ligados diretamente à falta de trabalho, o que pode implicar em uma questão anterior, a ausência de competência necessária para identificar oportunidades, para localizá-las, como, por exemplo, o entendimento que é importante se cadastrar em agências de emprego e visitar semanalmente essas agências. E6 ponderou justamente sobre essa questão durante o grupo focal, de ir ao encontro das oportunidades, de identificá-las.

Da mesma forma que é importante tentar compreender o que as empresas buscam, quais as características necessárias a um funcionário. A fala de E6 demonstra que ela se apropriou do conhecimento disseminado propiciando o desenvolvimento cognitivo, o que segundo Vygotsky (1991), ocorre se o aprendizado for adequadamente organizado. Conforme o autor para se construir conhecimento é preciso uma ação partilhada significando um processo de mediação entre sujeitos, através da interação, das relações com os outros e seu meio social, por isso, que qualquer função psicológica superior, se foi externa "[...] significa que ela foi social; antes de se tornar função, ela foi uma relação social entre duas pessoas." 


\section{Quadro 2 - Terceiro nível de codificação (durante grupo focal)}

\begin{tabular}{|c|c|c|}
\hline \multicolumn{3}{|c|}{ Avaliação da aprendizagem } \\
\hline $\begin{array}{l}\text { E6: Eu gostei muito. Prá [sic] } \\
\text { mim tudo foi bom como vocês } \\
\text { fizeram ... e eu entendi onde a } \\
\text { gente pode colocar o currículo } \\
\text { para as vagas. ... E também } \\
\text { onde a gente pode buscar. }\end{array}$ & $\begin{array}{l}\text { E10: Eu imaginava que seria } \\
\text { assim, como vocês falaram. }\end{array}$ & $\begin{array}{l}\text { E5: As informações foram } \\
\text { muito válidas, agora estou } \\
\text { saindo daqui com outro } \\
\text { pensamento e sei que vou me } \\
\text { sair bem nas entrevistas de } \\
\text { trabalho. }\end{array}$ \\
\hline $\begin{array}{l}\text { E3: Agora me sinto mais } \\
\text { preparada. Não sabia nada } \\
\text { disso. }\end{array}$ & $\begin{array}{l}\text { E2: Eu aprendi muito com } \\
\text { essa capacitação. A gente } \\
\text { precisa saber procurar e saber } \\
\text { se preparar. }\end{array}$ & $\begin{array}{l}\text { E7: Sinto mais confiança em } \\
\text { mim, nas coisas que eu sei } \\
\text { para mostrar na entrevista. }\end{array}$ \\
\hline $\begin{array}{l}\text { E1: Eu achei muito bom o } \\
\text { curso. A gente aprendeu } \\
\text { muito. E para esses jovens que } \\
\text { estão começando a vida e me } \\
\text { ajudam aqui é uma grande } \\
\text { coisa. }\end{array}$ & $\begin{array}{l}\text { E4: É verdade, eu penso assim } \\
\text { neh::: a gente precisa investir } \\
\text { na gente. Eu aprendi bem. }\end{array}$ & $\begin{array}{l}\text { E8: Foi bem explicadinho. Eu } \\
\text { não imaginava assim. Eu } \\
\text { gostei. Os vídeos foram } \\
\text { interessantes. Tem de saber se } \\
\text { comportar nas entrevistas. }\end{array}$ \\
\hline \multicolumn{3}{|c|}{ Conscientização da possiblidade de automodificabilidade (continuação quadro 2} \\
\hline $\begin{array}{l}\text { E7: Eu queria mesmo era } \\
\text { aprender como se comportar } \\
\text { numa entrevista de trabalho, } \\
\text { porque eu sabia apenas que o } \\
\text { currículo era importante, não } \\
\text { pensava nas outras coisas que } \\
\text { vocês explicaram. [...] Eu sei } \\
\text { que eu posso, vou correr atrás. }\end{array}$ & $\begin{array}{l}\text { E1: A gente precisa se } \\
\text { esforçar, tanta gente perde as } \\
\text { oportunidades. [...] É preciso } \\
\text { lutar para conseguir as coisas. } \\
\text { Isso aqui hoje é uma chance. } \\
\text { [...] Fazer um currículo bom } \\
\text { prá [sic] aquele emprego. }\end{array}$ & $\begin{array}{l}\text { E5: A gente que vive em } \\
\text { Comunidade pode conseguir } \\
\text { fazer faculdade. } \\
\text { [...] Tem preconceito, eu sei, } \\
\text { mas a gente precisa mostrar } \\
\text { que também consegue. }\end{array}$ \\
\hline $\begin{array}{l}\text { E8: A gente precisa lutar pra } \\
\text { melhorar as coisas neh:: : ... a } \\
\text { vida da gente. Eu já vou fazer } \\
\text { uns currículos depois mandar. }\end{array}$ & $\begin{array}{l}\text { E10: Agora com filho pequeno } \\
\text { é mais difícil, mas quando ele } \\
\text { crescer um pouco eu vou } \\
\text { atrás. Melhorar neh::: }\end{array}$ & $\begin{array}{l}\text { E6: A gente tem de correr } \\
\text { atrás ... ficar em casa não dá. } \\
\text { Pensar nas melhorias. Tem } \\
\text { tanto lugar pra a gente buscar } \\
\text { informação. }\end{array}$ \\
\hline \multicolumn{3}{|c|}{ Empoderamento das informações } \\
\hline $\begin{array}{l}\text { E4: Eu sei onde eu quero } \\
\text { chegar, conseguir os meus } \\
\text { sonhos. [...] Vou me preparar } \\
\text { muito agora. }\end{array}$ & $\begin{array}{l}\text { E3: O que eu aprendi aqui, eu } \\
\text { vou usar quando for procurar } \\
\text { trabalho ou estágio. }\end{array}$ & $\begin{array}{l}\text { E2: E a gente precisa saber } \\
\text { antes de ir para a entrevista } \\
\text { coisas sobre a empresa. } \\
\text { Pesquisar na internet. } \\
\text { Conversar com as pessoas que } \\
\text { a gente conhece. }\end{array}$ \\
\hline $\begin{array}{l}\text { E7: Agora eu sei, as empresas } \\
\text { querem pessoas responsáveis } \\
\text { e de confiança ... ah::: e } \\
\text { também que tenham vontade } \\
\text { de crescer. Ah::: quando eu } \\
\text { for para uma entrevista vou } \\
\text { com pouca maquiagem, blusa } \\
\text { comportada e calça. }\end{array}$ & $\begin{array}{l}\text { E8: Tudo que a gente } \\
\text { aprendeu aqui, as informações } \\
\text { que vocês deram. [...] Vamos } \\
\text { usar. Quero procurar um } \\
\text { trabalho e organizar minha } \\
\text { vida. Com o que eu aprendi } \\
\text { aqui eh::: posso fazer. }\end{array}$ & $\begin{array}{l}\text { E10: Pra [sic], mim foi muito } \\
\text { massa... ops [sic], foi muito } \\
\text { bom. Eu sei, temos de falar } \\
\text { bem numa entrevista. A } \\
\text { apresentação é muito } \\
\text { importante. [...] Eu vou } \\
\text { começar a me preparar } \\
\text { melhor. }\end{array}$ \\
\hline
\end{tabular}

Fonte: Dados da pesquisa 2014.

Ao avaliar o processo de aprendizagem, E1 contou que essa foi uma oportunidade de aprendizado para os jovens que estão começando a vida profissional. Essa percepção de E1 ocorre por ela ser a líder comunitária e desejar melhorias para os moradores, algo que sempre foi constatado durante quase seis anos de nossa atuação dentro da 
comunidade. As ações de E1 demonstram que ela acredita no poder de transformação que cada um possui dentro de si, por isso, ela procura estimular crianças e jovens por meio do trabalho realizado pela Associação, tentando conscientizá-los que é possível tornar a vida mais digna.

Esta reflexão nos leva a próxima categoria conscientização da possiblidade de automodificabilidade, e a fala de E5, ao esboçar que apesar do preconceito da sociedade ao olhar para os que vivem em comunidades, é preciso ultrapassar essa barreira e acreditar. Essa reflexão de E5 configura-se como um indício de conscientização, ainda latente, mas possível de concretização, através de passos ainda lentos, mas firmes no propósito de automodificabilidade. E6 demonstrou motivação em esboçar seu desejo em procurar melhorias, em buscar informações que a ajudem, a encontrar oportunidades de trabalho, pois ela se sente preparada após a qualificação, a participar de entrevistas.

A vontade e o desejo de mudar a atual situação em que se encontram, impulsionaram esses moradores a procurar possibilidades de aprendizado, de interagir com outras pessoas e caminharem para se tornarem protagonistas de suas próprias vidas, começando por se empoderarem das informações que necessitam. Segundo a Unesco (2009), o empoderamento permite aos cidadãos adquirir controle sobre suas próprias vidas.

É exatamente isso o que $\mathbf{E 8}$ anseia ao expressar que, todo o conteúdo apreendido durante a capacitação será colocado em prática, na busca por trabalho, ou seja, ela demonstra estar consciente do poder das informações que agora detêm. Percebeu-se neste contexto, que o empoderamento pode influenciar a vida dos indivíduos e contribuir para que eles atuem de forma ativa na construção das competências necessárias para transformarem suas realidades, o que ocorreu, por exemplo, com E7, que demonstrou ter compreendido quais são as características que geralmente as empresas buscam nos candidatos, bem como as qualificações específicas de cada vaga, ao afirmar que: "Agora eu sei, as empresas querem pessoas responsáveis e de confiança, ... ah:: : e também que tenham vontade de crescer."

É preciso ressaltar que, temos convicção de que o empoderamento é um conceito complexo e indica, conforme Cappelletti e Martinelli (2010), um processo utilizado para designar o conjunto de conhecimentos, aptidões e habilidades interpessoais. Além disso, Horochovski e Meirelles (2007) alertam que o empoderamento é uma variável multidimensional, e não pode ser generalizada, como algo que se tem ou não de forma absoluta, ou seja, há graus de empoderamento, nunca se é totalmente empoderado, daí a importância do processo de conscientização por parte dos cidadãos do controle de suas próprias vidas, e do trabalho em comunhão com os outros indivíduos para construir estratégias e ações, visando atingir os objetivos traçados coletivamente, a fim de obter os recursos necessários para toda a comunidade.

Nesta perspectiva, o mediador, que atua em uma comunidade, pode ajudar os moradores, levando ao conhecimento dos interessados, os 
aspectos que envolvem alguns graus de empoderamento e a necessidade de discussão de todas as informações necessárias para se pleitear políticas, projetos e ações.

\subsection{Competências dos moradores}

Os dados acima analisados indicam que o objetivo principal da capacitação foi alcançado, o de propiciar/estimular, por meio de conteúdos e metodologias específicas, o desenvolvimento da consciência nos participantes da importância de se empoderar das informações necessitadas e transformá-las em ação - um processo que teve a mediação como base em todas as fases.

Estes dados ainda demonstram que há indícios, de que os participantes conseguiram atingir um dos itens do empoderamento: a preparação para o trabalho por meio do desenvolvimento de determinadas competências (apresentadas no Quadro 3), as quais estão diretamente conectadas aos objetivos específicos da capacitação, e, consequentemente, ao conteúdo disseminado, quais sejam: como preparar um currículo direcionado para a vaga desejada; como obter o maior número possível de informações a respeito da empresa que se deseja trabalhar; qual o vestuário apropriado; como se comunicar adequadamente (linguagem verbal e corporal); como desenvolver a capacidade de antever possíveis questionamentos do entrevistador; a relevância da habilidade de ser proativo quanto às informações a serem respondidas; a importância de responder aos questionamentos de forma verdadeira (não mentir); qual o perfil de profissional que as empresas buscam; e quais as fontes de informação para futuras pesquisas sobre a temática.

Compreendeu-se que esses objetivos estão diretamente ligados às competências conceituadas por Le Boterf (2003): saber agir com pertinência; saber mobilizar saberes e conhecimentos em um contexto profissional; saber integrar ou combinar saberes múltiplos e heterogêneos; saber transpor; saber aprender e aprender a aprender; e saber envolver-se. A relação entre os objetivos específicos da capacitação e as competências de Le Boterf pode ser visualizada no Quadro 3. 


\section{Quadro 3 - Relação entre objetivos específicos e competências}

\begin{tabular}{|l|l|}
\hline \multicolumn{1}{|c|}{ Objetivos específicos } & \multicolumn{1}{c|}{ Competências } \\
\hline $\begin{array}{l}\text { Desenvolver a habilidade de ser proativo } \\
\text { quanto às informações a serem respondidas; } \\
\text { Responder aos questionamentos de forma } \\
\text { verdadeira (não mentir); }\end{array}$ & $\begin{array}{l}\text { Saber agir com pertinência em cada nova } \\
\text { situação, tomando decisões ponderadas em } \\
\text { ocasiões imprevistas. }\end{array}$ \\
\hline $\begin{array}{l}\text { Preparar um currículo direcionado para a vaga } \\
\text { desejada; }\end{array}$ & $\begin{array}{l}\text { Saber integrar ou combinar saberes } \\
\text { múltiplos e heterogêneos, procurando } \\
\text { utilizar os recursos disponíveis para obter } \\
\text { sucesso nas atividades empreendidas. }\end{array}$ \\
\hline $\begin{array}{l}\text { Obter o maior número possível de informações } \\
\text { a respeito da empresa que se deseja trabalhar; }\end{array}$ & $\begin{array}{l}\text { Saber mobilizar saberes e conhecimentos } \\
\text { em um contexto profissional mobilizando } \\
\text { conhecimentos teórico-práticos. }\end{array}$ \\
\hline $\begin{array}{l}\text { Desenvolver a capacidade de antever possíveis } \\
\text { questionamentos do entrevistador; }\end{array}$ & $\begin{array}{l}\text { Saber transpor as barreiras físicas e } \\
\text { cognitivas, não se limitando ao que parece ser } \\
\text { evidente. }\end{array}$ \\
\hline $\begin{array}{l}\text { Compreender o perfil de profissional que as } \\
\text { empresas buscam; }\end{array}$ & $\begin{array}{l}\text { Saber aprender e aprender a aprender, } \\
\text { colocando em prática os conhecimentos teóricos } \\
\text { e práticos adquiridos durante a capacitação, } \\
\text { procurando refletir a partir das experiências } \\
\text { adquiridas a cada oportunidade (entrevista } \\
\text { realizada). }\end{array}$ \\
\hline $\begin{array}{l}\text { Apresentar as fontes de informação para } \\
\text { futuras pesquisas sobre a temática. }\end{array}$ & $\begin{array}{l}\text { Saber envolver-se com a situação } \\
\text { cada vez mais melhorias para si e para sua } \\
\text { comunidade. }\end{array}$ \\
\hline
\end{tabular}

Fonte: Dados da pesquisa, 2014 e competências de Le Boterf (2003).

Todas essas competências objetivam habilitar o indíviduo a identificar suas necessidades informacionais e até mesmo as do seu grupo, buscando as informações que lhe são úteis para solucionar as situações-problema. A coluna à direita do quadro acima apresenta um esquema concebido por Le Boterf (2003) para demonstrar a operacionalização das competências e seus parâmetros melhor explicitados a seguir:

Saber agir com pertinência - o profissional deve adquirir competência para atuar em cada nova situação, tomando decisões ponderadas em ocasiões imprevistas. É preciso se antecipar, procurar antever problemas, ir além do que é evidente, mostrando-se, por exemplo, proativo no momento de uma entrevista de trabalho, respondendo prontamente aos questionamentos de forma verdadeira e se dispondo a aprender continuamente, para ocupar plenamente a vaga almejada.

Saber integrar ou combinar saberes múltiplos e heterogêneos - o candidato a uma vaga deve saber utilizar os recursos disponíveis para obter sucesso nas atividades empreendidas, reunindo todos esses recursos e saberes para resolver problemas, formulando estratégias, a exemplo da preparação de um currículo direcionado para a vaga desejada, confeccionando-o com atenção voltada também para o perfil da empresa. Por isso, nesse caso, precisa-se integrar saberes múltiplos, produzindo não apenas um simples currículo, mas sim, um documento com credibilidade para obter a vaga. 
Saber mobilizar saberes e conhecimentos - em um contexto profissional o indivíduo deve saber mobilizar conhecimentos teóricopráticos, pois a competência só existe quando é colocada em ação. Esse saber está conectado ao anterior, pois antes da produção do currículo, o candidato deve obter o maior número possível de informações a respeito da empresa, na qual deseja trabalhar, para se preparar para a entrevista com foco na vaga e de acordo com a política da empresa escolhida, colocando verdadeiramente os saberes e conhecimentos em ação.

Saber transpor - o profissional precisa aprender a superar as barreiras físicas e cognitivas, não se limitar ao que parece ser evidente ou a situações de estresse e problemáticas; ele deve agir. Durante a capacitação trabalhamos esse parâmetro, apresentando a importância de antever possíveis questionamentos do entrevistador, e de se mostrar hábil para superar obstáculos diários durante a execução das tarefas dentro da empresa.

Saber aprender e aprender a aprender - o profissional deve colocar em prática os conhecimentos adquiridos durante a capacitação, procurando refletir a partir das experiências adquiridas a cada oportunidade (entrevista realizada), isto é, refletir a partir das ações, das lições diárias e utilizar isso para seu aprimoramento. Ao compreender o perfil do profissional que as empresas buscam, o candidato estará um passo a frente dos concorrentes, e mesmo que a primeira entrevista não tenha sido promissora, as próximas serão realizadas com mais segurança e com a experiência de quem compreendeu a necessidade de aprender a aprender.

Saber envolver-se - com o trabalho e com o grupo na empresa, demonstrando iniciativa, podendo, inclusive assumir riscos, pois é assim que surgem as promoções, as novas oportunidades de crescimento. Envolver-se também com a situação apresentada e se sentir estimulado a buscar cada vez mais melhorias para si e para sua comunidade, procurando, por exemplo, fontes de informação para futuras pesquisas sobre entrevistas de trabalho, além de procurar saber quais as características que as empresas desejam nos funcionários. Como afirma Le Boterf (2003), o indivíduo reconhecido como um profissional competente possui uma identidade social, que vai além do emprego que ocupa.

As competências acima listadas podem ser utilizadas como parâmetro, para a interpretação do que foi apreendido pelos participantes, podendo ainda acionar nossos recursos cognitivos para resolver problemas, o que conforme Torres (2007), se traduz na capacidade de uma pessoa ser capaz de agir de maneira eficaz diante de uma determinada situação, ao utilizar seus conhecimentos/experiências, mas sem limitar-se exclusivamente a eles. A autora enfatiza que é exatamente por meio das nossas competências - as quais são expressas por um conjunto de habilidades (estratégias e procedimentos de ação) -, que manifestamos as possibilidades de enfrentar e resolver situaçõesproblema. 
Isso ocorre, porque o entendimento da lógica da competência passa pela compreensão do ideário histórico que norteou a formação do sujeito e os modos do trabalho ao longo dos movimentos de cunho político, econômico e social que ordenaram a sociedade. Por isso, Varela, Barbosa e Farias (2014) afirmam que, ser competente não é apenas responder a um estímulo e realizar uma série de comportamentos, mas, sobretudo ser capaz de, voluntariamente, selecionar as informações necessárias para regular sua ação ou mesmo inibir as reações inadequadas. Na realidade, essa concepção pretende superar a falta de sentido existente na mera consecução de objetivos, entretanto, a competência não é redutível aos comportamentos estritamente objetivos, mas está vinculada sempre a uma atividade humana que, seja ligada à escola ou ao trabalho, e se caracteriza por sua relação funcional com tais atividades definidas socialmente.

A manifestação das competências gira, de acordo com Le Boterf (2003, p. 37), em torno da capacidade que o profissional tem em administrar uma situação complexa, numa referência à complexidade dos processos do trabalho na atualidade, por isso, o papel do profissional será o de traçar e executar um percurso, ou seja, elaborar e conduzir um projeto, considerando "[...] o campo de forças e as imposições diversas e, às vezes, opostas, que constituem a complexidade". Cada fase cria uma situação nova que deve ser avaliada para dar origem a um novo percurso.

$\mathrm{Na}$ execução do percurso, o profissional lança mão de vários recursos e processos. Essa visão de Le Boterf está em consonância com o pensamento de Zarifian (2001), quando este afirma que a competência é o entendimento prático de situações apoiadas em conhecimentos adquiridos e os transforma a cada nova e diferente situação, a cada entrevista de trabalho realizada.

Ao final, conclui-se, com base nas reflexões de Le Boterf (2003) e Zarifian (2001), que as competências nascem no âmbito trabalhista, o que reforça a certeza da escolha adequada para a temática da capacitação, uma escolha realizada pelos próprios moradores. Observa-se ainda que, para ser considerado "empregável", o candidato a uma vaga precisa desenvolver competências desejadas pelo mercado de trabalho, pela empresa, na qual objetiva trabalhar. E após conseguir a vaga, esse desenvolvimento de competências é constante, e se constitui em um requisito para o profissional crescer e até mesmo se manter dentro da empresa, por isso, a integralização de saberes deve ser constante, o saber agir, envolver-se e aprender a aprender.

\section{Considerações finais}

Ao concluir uma pesquisa cujos fundamentos teóricos foram se desenvolvendo de forma empírica, em uma realidade complexa e dinâmica como uma comunidade, compreende-se que é nas práticas sociais que se pode observar determinados conceitos tomando forma, interagindo e perpassando diversas áreas do conhecimento. 
Nesta perspectiva, é preciso se reportar à mediação da informação que forneceu subsídios teóricos para esta pesquisa transitar na Ciência da Informação, o que possibilitou a potencialização do protagonismo social nos moradores da comunidade, ao passarem por alguns estágios de empoderamento da informação, ao se apropriarem dela e a utilizarem para desenvolver um conjunto de conhecimentos, aptidões e habilidades, como demostrado na análise e interpretação dos dados coletados durante a capacitação e o grupo focal. Percebeu-se nas falas dos moradores o interesse em se empoderarem da informação, propiciando o surgimento da consciência do valor que a informação tem em suas vidas.

Estes elementos fazem parte de todo o aporte teórico e empírico desta investigação, os quais foram construídos visando fornecer instrumentos para realizar a pesquisa de campo e atingir os objetivos propostos, bem como ver aflorar os objetivos que estão aparentemente "implícitos" no coração desta pesquisa, que é o de contribuir para que os sujeitos da pesquisa possam iniciar um movimento de socialização, de busca da consciência crítica, do entendimento da sua realidade social, de valorização do seu poder de estar na sociedade e dela participar. Destarte, considera-se como fundamental a mediação promovida pelo profissional da informação, incentivando a disseminação e construção de cultura, crenças, valores e conhecimento de um determinado grupo, de uma determinada comunidade.

Em relação às competências detectadas nos moradores/participantes da capacitação, foi possível verificar indícios de habilidades, conhecimentos e saberes como: procurar antever problemas, ir além do que é evidente, mostrando-se proativo no momento de uma entrevista de trabalho, respondendo prontamente aos questionamentos de forma verdadeira e se dispondo a aprender continuamente, para ocupar plenamente a vaga almejada; saber utilizar os recursos disponíveis para obter sucesso nas atividades empreendidas, formulando estratégias, obter o maior número possível de informações a respeito da empresa, na qual deseja trabalhar, procurar antever possíveis questionamentos do entrevistador, e de se mostrar hábil para superar obstáculos diários durante a execução das tarefas dentro da empresa; saber compreender o perfil do profissional que as empresas buscam, aprender a aprender, saber envolver-se também com a situação apresentada e se sentir estimulado a buscar cada vez mais melhorias para si e para sua comunidade. Dessa forma, a preparação para o acesso ao mundo do trabalho se configura como sendo um das dimensões para se chegar ao protagonismo social.

Pode-se observar na comunidade pesquisada como as interações sociais se constituem em um espaço social, onde a ação de informação ocorreu em um movimento de reconstrução desse espaço físico, tornandoo um lugar repleto de representações e de manifestações culturais, sociais e históricas. Infere-se que a ação de informação realizada para e com os moradores produziu conhecimentos, principalmente, a interação dos sujeitos com o meio onde vivem, a partir da carga cultural e histórica que eles trazem o que está intrinsicamente ligado à prática social. 
Nesta perspectiva, esforços devem ser empreendidos para identificar barreiras na mediação e vencê-las pelos canais de comunicação, das fontes, das possibilidades, da comunicação oral, identificando qual a linguagem usar nesse contexto social da comunidade, e quais os meios comunicacionais utilizados para melhorar as barreiras. Transcender a definição de mediador para ressignificar e transformar o mundo, pode provocar o fortalecimento de constructos teóricos da mediação da informação.

\section{Referências}

ALMEIDA, M. A. de. A produção social do conhecimento na sociedade da informação. Informação \& Sociedade: estudos, Londrina, v. 19, n. 1, p. 11-18, 2009.

ALMEIDA JÚNIOR, O.F. de. Mediação da informação: um conceito atualizado. In: BORTOLIN, S.; SANTOS NETO, J.A. dos; SILVA, R.J. da. (Org.). Mediação oral da informação e da leitura. Londrina: Abecin, 2015. p.9-32.

BARDIN, L. Análise de conteúdo. Tradução: Luís Antero reto e Augusto Pinheiro. 4. ed. rev. e atual. Lisboa: Edições 70, 2009.

BRANDÃO, C. R. Pesquisar-Participar. In: BRANDÃO, C.R. (Org.). Pesquisa participante. 3. ed. São Paulo: Editora Brasiliense, 1983, p. 09-17.

CAPPELLETTI, P.; MARTINELLI, M. Animare la città. Percorsi di community building. Trento, Itália: Erickson, 2010.

FARIAS, M.G.G. Mediação e competência em informação: proposições para a construção de um perfil de bibliotecário protagonista. InCID: R. Ci. Inf. e Doc., Ribeirão Preto, v. 6, n. 2, p. 106-125, set. 2015/fev. 2016. Disponível

em:

http://www.revistas.usp.br/incid/article/view/101368/103968.

Acesso em: 04 nov. 2015.

FARIAS, M.G.G.; FREIRE, I.M. A realidade dos quartieri sensibili na Itália: a informação como instrumento de transformação social. Tendências da Pesquisa Brasileira em Ciência da Informação, João Pessoa, v.7, n.2, p. 212-23, jul./dez. 2014.

FEUERSTEIN, R. Instrumental enrichment: an intervention program for cognitive modifiability. Baltimore: University Park Press, 1980.

FUNDAÇÃO LUÍS EDUARDO MAGALHÃES (FLEM). Capacitação de lideranças comunitárias: uma experiência de gestão compartilhada para o combate à pobreza. Salvador: Flem, 2004.

GOHN, M. da G. Empoderamento e participação da comunidade em políticas sociais. Saúde e Sociedade, v.13, n.2, p.20-31, maio-ago., 2004.

GOMES, H. F. A dimensão dialógica, estética, formativa e ética da mediação da informação. Informação \& Informação, Londrina, v. 19, n. 2, p. 46 - 59, maio/ago. 2014. Disponível em: 
http://www.uel.br/revistas/uel/index.php/informacao/article/view/19994. Acesso em: 29 jul. 2015.

GOMES, R. A análise de dados em pesquisa qualitativa. In: MINAYO, M. C. de S. Pesquisa social: teoria, método e criatividade. Petrópolis, RJ: Vozes, 1994, p. 67-80.

HOROCHOVSKI, R. R.; MEIRELLES, G. Problematizando o conceito de empoderamento. In: SEMINÁRIO NACIONAL MOVIMENTOS SOCIAIS, PARTICIPAÇÃO E DEMOCRACIA, 2, Núcleo de Pesquisa em Movimentos Sociais - NPMS, Florianópolis, [Anais..], Florianópolis: UFSC, 2007. p.485-506.

KLEIN, Otavio J. Para compreender o protagonismo social na construção do telejornalismo em rede. In: CONGRESSO BRASILEIRO DE CIÊNCIAS DA COMUNICAÇÃO, XXXII, 2009, Curitiba. [Anais...], Curitiba: Intercom Sociedade Brasileira de Estudos Interdisciplinares da Comunicação, 2009. p.1-13.

LE BOTERF, G. Desenvolvendo a competência dos profissionais. 3. ed. rev. ampl. Porto Alegre: Artmed, 2003.

PERRENOUD, P. Construir as competências desde a escola. Porto Alegre: Artmed, 1999.

PERROTTI, E.; PIERUCCINI, I. Infoeducação: saberes e fazeres da contemporaneidade. In: LARA, Marilda L. Ginez de; FUJINO, A.; NORONHA, D. P. (Orgs.). Informação e contemporaneidade: perspectivas. Recife: Néctar, 2007. p. 47-96.

PINTO MOLINA, M. Habilidades y competencias de gestión de información para aprender a aprender en el Marco del Espacio Europeo de Enseñanza Superior. Granada: Universidad de Granada, 2005. (Portal ALFIN - EEES). Disponível em: http://www.um.es/dp-lenguaespa/documentos/habilidades-competencias.pdf. Acesso em: dez. 2013.

SANTOS, E. L.; PIERUCCINI, I. Infoeducação e cultura quilombola: uma perspectiva de diálogo entre sujeitos e saberes. Revista da Associação Brasileira de Pesquisadores(as) Negros(as) - ABPN, São Paulo, v. 3, p. 95-111, 2012.

TAVARES, R. B. Comunicação da informação em comunidades que leva em conta letramento informacional e trabalho colaborativo para desenvolvimento de cidadania. 2011. 246f. Tese (Doutorado em Ciência de Informação) - Programa de Pós-Graduação em Ciência da Informação, Universidade de Brasília, Brasília, DF, 2011.

TORRES, M. Z. Situações-problema como recurso de avaliação de competências no Enem. In: MINISTÉRIO DA EDUCAÇÃO. (Org.). Eixos cognitivos do Enem, Brasília, 2007, p. 31-53.

UNESCO. Freedom of Expression, Access to Information and Empowerment of People. Paris: United Nations Educational, Scientific and Cultural Organization, 2009. 
VARELA, A. V.; BARBOSA, M.; FARIAS, M. G. G. Mediação em múltiplas abordagens. Inf. Inf., Londrina, v. 19, n. 2, p. 138 - 170, maio./ago. 2014.

VARELA, A.V. Informação, cognição e mediação: vertentes, contextos e pretextos. Revista Iberoamericana de Ciência da Informação, Brasília, v. 1, p. 21-45, 2008.

VEIGA, L.; GONDIM, S.M.G. A utilização de métodos qualitativos na ciência política e no marketing político. Opinião Pública, Campinas-SP, v.2, n.1, p. 1-15, 2001.

VYGOTSKY, L. S. A formação social da mente: o desenvolvimento dos processos psicológicos superiores. 4. ed. São Paulo: Martins Fontes, 1991.

ZARIFIAN, P. Objetivo competência: por uma nova lógica. São Paulo: Atlas, 2001. 
No artigo Competência em informação para comunidades: empoderamento e protagonismo social, com número de DOI: 10.1590/1981-5344/2614, publicado no periódico Revista Perspectivas em Ciência da Informação, 24(1):4-24, na página 4:

Onde se lia:

Isa Maria Freira ${ }^{I I I}$

Leia-se:

Isa Maria Freire ${ }^{I I I}$

No cabeçalho, onde se lia:

Isa Maria Freira

Leia-se:

Isa Maria Freire 